\title{
Pengolahan Citra Negatif Klise Menjadi Citra True Color Dengan Matlab
}

\section{Transforming Negative Image Cliche into True Color Image by Matlab}

\author{
Dhanar Intan Surya Saputra', Muhammad Agus Triwibowo², Muhammmad Faiz Noeris ${ }^{3}$, \\ Maskur Alasad ${ }^{4}$ \\ 1,2,3,4 STMIK AMIKOM Purwokerto; Jl. Letjen Pol Sumarto, Purwanegara, Purwokerto Utara, \\ Indonesia 53123, 0281-623321. \\ 1,2,3,4 Program Studi Teknik Informatika \\ 1' dhanarsaputra@ amikompurwokerto.ac.id, ${ }^{2}$ m.a.triwibowo@ gmail.com, \\ ㄹ‥faiznoeris@gmail.com, ${ }^{3}$ almaskoer@gmail.com
}

\begin{abstract}
Abstrak
Dalam proses cetak foto, saat ini sangatlah mudah, menggunakan flasdisk atau memori lainnya dan komputer maka langsung dapat dicetak, baik dilakukan secara individu atau melalui studio foto. Proses tersebut tentunya mempermudah bagi siapapun pengguna fotografi. Namun, permasalahannya bagaimana dengan masyarakat yang masih memiliki klise foto dan ingin mencetaknya (afdruk), sedangkan saat ini hanya beberapa studio foto yang masih membuka jasa proses cetak foto klise (negative foto/ film). Maka dalam penelitian ini dilakukan pengembangan sebuah aplikasi dan alat untuk mendapatkan citra true color dari klise secara mandiri. Aplikasi berbasis komputer untuk pengolahan citra negatif menjadi citra true color yang menggunakan fungsi dari matlab merupakan proses memasukkan informasi berupa citra negatif yang diakuisisi dengan menggunakan alat scan klise sederhana ke dalam komputer. Selanjutnya komputer mengolah citra negatif yang telah dimasukkan dan memberikan keluaran yang berupa citra true color. Aplikasi yang dikembangkan meliputi proses pilih gambar, proses grayscale, proses simpan gambar, proses reset, proses kirim via email. Dalam aplikasi adanya penambahan fitur seperti memberikan keluaran yang berupa grayscale, dan juga histogram dari citra yang telah diproses, fitur lainnya adalah mengirim citra hasil pengolahan melalui email dan menyimpan hasil citra kedalam komputer. Hasil dari proses citra, aplikasi dapat melakukan penyimpanan dalam format JPG/JPEG (Joint Photographic Expert Group), yang mampu untuk menyimpan gambar dengan mode warna RGB (Red, Green dan Blue).
\end{abstract}

Kata kunci-GUI, Matlab, klise, negatif, true color

In photo-printing process, the usage of flashdisk or other kind of memory and computer is sufficient to change from digital into printed photo, either done individually or by photo studio. That process certainly helps everybody in using photography. Yet, the problem lies in the fact that there are still people possessing cliche photos and willing to print while the number of photo studios are recently rare. So by this research, we have developed an application to get true color image from cliche. Computer-based application to transform negative image into true color image uses the function of matlab, it runs as negative image acquired by the cliche scanner into computer. Computer processes the negative image until transformed into true color image come out as an output. The developed application consists of image selection, grayscale process, image saving process, reset process, sending via email process. There are 
additional features such as grayscale image and also histogram from the processed image, another feature is to sind the processed image via email and/or to save them in the computer. Computer enables to save images in JPG/JPEG (Joint Photographic Expert Group), that able to save image with color mode RGB (Red, Green, and Blue).

Keywords-GUI, Matlab, cliché, negative, true color

\section{PENDAHULUAN}

Perkembangan teknologi fotografi yang begitu cepat saat ini dapat dijadikan tolak ukur bahwa ilmu pengetahuan menjadi pemicu tumbuh dan berkembangnya aplikasi fotografi dalam berbagai bidang kehidupan manusia. Fotografi bukan hanya sebagai media dokumentasi saja, melainkan dapat juga sebagai media dalam menampung segala bentuk ekspresi diri dari setiap pengalaman masing-masing individu.

Perkembangan teknologi yang terkait dengan pemrosesan menggunakan komputer sudah semakin pesat, dimana pemrosesan image (citra) sudah menggunakan teknologi digital. Seiring dengan berkembangnya teknologi grafis maka gambar dimanfaatkan sepenuhnya untuk memajukan kesejahteraan umat manusia, serta perkembangan kreatifitas gambar tidak lepas dari pengolahan citra digital. Gambar (image, picture) adalah kombinasi antara titik, garis, bidang, dan warna untuk menciptakan suatu imitasi atau tiruan dari suatu obyek fisik, benda atau barang (manusia, binatang, tumbuhan, buah, dsb)[1]. Penelitian di bidang pengolahan citra digital sangatlah luas, seperti mengenai wajah, pengenalan wajah, menggunakan teknologi pelacakan (tracking) dan deteksi wajah, pengolahan citra dan beberapa implementasi lainnya [2].

Pada era ini, walaupun teknologi konvensional atau proses manual hampir ditinggalkan tetapi masyarakat masih kebanyakan menyimpan foto mereka dalam bentuk gulungan klise. Klise merupakan lembaran yang menyimpan hasil foto kedalam bentuk foto negatif, yang jika ingin dicetak harus dibawa ke percetakan foto untuk dilakukan proses pencucian, kemudian menjadi foto fisik dengan warna yang sesungguhnya dan dalam ukuran yang diinginkan. Mengingat sudah hampir tidak adanya masyarakat yang menggunakan perangkat fotografi yang menggunakan gulungan klise, maka tempat percetakan foto untuk mencuci klise sudah sangat jarang. Namun beberapa orang masih memiliki klise yang belum sempat dicetak, ataupun yang foto fisiknya sudah rusak.

Pengolahan citra merupakan proses pengolahan dan analisis citra yang banyak melibatkan persepsi visual. Proses ini mempunyai ciri data masukan dan informasi keluaran yang berbentuk citra. Citra adalah suatu representasi (gambaran), kemiripan atau imitasi dari suatu objek. Citra yang berupa output dari suatu sistem perekaman data dapat bersifat optik berupa foto, bersifat analog berupa sinyal-sinyal video seperti gambar pada monitor televisi atau bersifat digital yang dapat langsung disimpan pada suatu media penyimpanan. Citra mempunyai karakteristik yang tidak dimiliki oleh data teks, yaitu kaya dengan informasi [3]. Citra yang terlihat merupakan cahaya yang direfleksikan dari sebuah objek. Sumber cahaya menerangi objek, objek memantulkan kembali sebagian dari berkas cahaya tersebut dan pantulan cahaya ditangkap oleh alat-alat optik, misal mata manusia, kamera, scanner, sensor satelit, kemudian direkam. Citra seperti ini dapat dikategorikan kedalam dua macam yaitu Citra Kontinu merupakan citra yang dihasilkan dari sistem optik yang menerima sinyal analog. Contoh : mata manusia, kamera analog. Citra Diskrit / Citra Digital merupakan citra yang dihasilkan melalui proses digitalisasi terhadap citra kontinu. Contoh : kamera digital, scanner [4].

Pemanfaatan citra analog saat ini sudah sangat jarang dimanfaatkan karena tidak dapat direpresentasikan dalam komputer sehingga tidak bisa diproses secara langsung, tetapi jika ingin memproses citra ini di komputer, harus melalui proses konversi analog ke digital. Citra analog adalah citra yang bersifat kontinu, seperti gambar pada monitor televisi, foto sinar X, foto yang tercetak dikertas foto, lukisan, pemandangan alam, hasil CT scan dan lain sebagainya. 
Citra analog dihasilkan dari alat-alat analog diantaranya adalah video kamera analog, kamera foto analog dan CT scan [5]. Citra digital adalah citra yang bersifat diskrit yang dapat diolah oleh komputer yang merupakan suatu array dari bilangan yang merepresentasikan intensitas terang pada point yang bervariasi (piksel). Piksel ini menghasilkan raster data citra. Suatu ukuran citra yang umum adalah 640 x 480 piksel dan 256 warna ( 8 bit per piksel) dan akan berisi kira-kira 300 kilobyte data. Citra ini dapat dihasilkan melalui kamera digital dan scanner ataupun citra yang telah mengalami proses digitalisasi. Citra digital disimpan juga secara khusus di dalam file 24-bit atau 8-bit. Citra 24- bit menyediakan lebih banyak ruang untuk menyembunyikan informasi. Semua variasi warna untuk piksel yang diperoleh dari tiga warna dasar: merah, hijau dan biru. Setiap warna dasar direpresentasikan dengan 1 byte, citra 24-bit menggunakan 3 byte per piksel untuk merepresentasikan suatu nilai warna dan 3 byte ini dapat direpresentasikan sebagai nilai hexadecimal, decimal, dan biner [5].

Setiap pixel pada citra warna mewakili warna yang merupakan kombinasi dari tiga warna dasar (RGB=Red Green Blue) setiap warna dasar menggunakan penyimpanan 8 bit $=1$ byte, yang berarti mempunyai gradasi sebanyak 225 warna berarti setiap piksel mempunyai kombinasi warna sebanyak $2^{8} \cdot 2^{8} \cdot 2^{8}=224=16$ juta warna lebih. Penyimpanan citra true color didalam memori berbeda dengan citra grayscale. Setiap piksel dengan citra grayscale 256 gradasi warna diwakili oleh 1 byte. Sedangkan 1 piksel citra true color diwakili oleh 3 byte yang masing-masing byte merepresentasikan warna merah (Red), hijau (Green), biru (Blue) [6].

Meskipun sebuah citra kaya informasi, namun seringkali citra yang kita miliki mengalami penurunan mutu (degradasi), misalnya mengandung cacat atau derau (noise), warnanya terlalu kontras, kurang tajam, kabur (blurring), dan sebagainya. Tentu saja citra semacam ini menjadi lebih sulit diinterpretasi karena informasi yang disampaikan oleh citra tersebut menjadi berkurang. Agar citra yang mengalami gangguan mudah diinterpretasi (baik oleh manusia maupun mesin), maka citra tersebut perlu dimanipulasi menjadi citra lain yang kualitasnya lebih baik.

Melakukan penelitian akuisisi citra digital untuk mendapatkan citra hasil segmentasi yang dapat diklasifikasikan berdasarkan ektraksi citra RGB, intensitas density, dan derajat keabuan. Dimana hasil citra yang telah diterima kemudian diproses kedalam suatu pemrograman Grafic Usher Interface (GUI) pada matlab. Hasil segmentasi yang didapatkan pada ekstraksi RGB dari gambar hasil pengujian ini dapat diketahui bahwa intensity distribution untuk citra warna Red (R) sama dengan citra warna Blue (B) yaitu 2. Sedangkan untuk ekstraksi citra warna Green $(G)$ adalah 11. Serta, hasil tekstur dari segmantasi citra warna Blue (B), menghasilkan citra yang jauh lebih baik dari segmentasi citra yang lain [8].

Membuat aplikasi secara GUI dari MATLAB untuk merubah detail dan warna sebuah file gambar menjadi lebih kecil tanpa terlihat mencolok dari pandangan manusia sehingga menghemat penggunaan memori dan media penyimpanan. Hasil yang didapat yaitu aplikasi MATLAB dapat membantu dalam mengkompresi atau menghilangkan berbagai kerumitan yang tidak penting (redundansi) dari suatu informasi dengan cara memadatkan isi file sehingga ukurannya menjadi lebih kecil dengan memaksimalkan kesederhanaannya dan tetap menjaga kualitas penggambaran dari informasi tersebut dengan memakai fungsi dasar yang ada pada MATLAB [9].

Menerapkan pengolahan citra digital dengan MATLAB 7.1 pada citra radiografi untuk mengetahui klasifikasi nondestructive testing. Hasil penelitan menunjukkan adanya peningkatan kualitas pada citra radiografi, sehingga dapat digunakan untuk mengetahui klasifikasi nondestructive testing [10].

Pada penelitian ini, peneliti melakukan penelitian yang bertujuan untuk mengembangkan sebuah aplikasi dan alat yang memudahkan masyarakat untuk mendapatkan citra true color dari klise secara mandiri dengan menggunakan aplikasi Matlab, dalam aplikasi tersebut peneliti juga menambahkan beberapa fitur tambahan seperti memberikan output yang berupa grayscale, dan juga histogram dari citra yang telah diproses, fitur lainnya adalah mengirim citra hasil pengolahan melalui email dan menyimpan hasil citra kedalam komputer. 


\section{METODE PENELITIAN}

Metode penelitian dari penelitian ini adalah membangun aplikasi pengolahan citra negatif menjadi citra true color dengan memanfaatkan perangkat lunak MATLAB. MATLAB merupakan bahasa tingkat tinggi dan lingkungan interaktif yang memungkinkan untuk melakukan tugas-tugas komputasi secara intensif lebih cepat dibandingkan dengan bahasa pemrograman tradisional seperti $\mathrm{C}, \mathrm{C}++$, dan Fortran. Matlab adalah sebuah lingkungan komputasi numerikal dan bahasa pemrograman komputer generasi keempat. Matlab memungkinkan manipulasi matriks, pem-plot-an fungsi dan data, implementasi algoritma, pembuatan antarmuka penggguna, dan pengantarmukaan dengan program dalam bahasa lainnya. Meskipun hanya bernuansa numerik, sebuah toolbox yang menggunakan mesin simbolik MuPAD, memungkinkan akses terhadap kemampuan aljabar komputer. Sebuah paket tambahan, Simulink, menambahkan simulasi grafis multiranah, dan Desain berdasar-Model untuk sistem terlekat dan dinamik [7].

Data citra negatif diambil dengan menggunakan kamera yang formatnya berekstensi *.jpg sebagai masukkan yang kemudian diubah menjadi citra true color.

\section{HASIL DAN PEMBAHASAN}

1. Bahan Penelitian

Penelitian ini menggunakan bahan inputan berupa file data citra negative yang diambil menggunakan kamera dengan format ekstensinya *.jpg sebagai masukan yang kemudian diubah menjadi citra true color.

2. Pemilihan Perangkat Lunak dan Perangkat Keras

Dalam melakukan implementasi dan pengkonstruksian aplikasi dari mode rancangan menjadi sebuah aplikasi jadi, pada penelitian ini digunakan perangkat lunak MATLAB R2016a, dan perangkat keras Laptop Lenovo G400 dengan spesifikasi prosesor Intel® Pentium ${ }^{\circledR} 2020 \mathrm{M}$ @2.4Ghz, 4GB of RAM, Video Card AMD Radeon ${ }^{\mathrm{TM}}$ HD8570 2GB, sistem operasi Microsoft Windows 10 Pro.

3. Alur Algoritma

Alur perancangan algoritma yang digunakan untuk membuat aplikasi ini adalah dengan melakukan tahapan pembuatan suatu system pengolahan citra yang mampu mengubah citra negative menjadi true color.

Seperti terlihat pada gambar, sistem ini akan melakukan proses pengolahan citra digital yaitu dengan proses load image (pilih gambar), proses grayscale, proses true color, proses histogram, proses save image (simpan gambar), dan dari hasil pengolahan citra tersebut dapat di simpan atau di kirim melalui email.

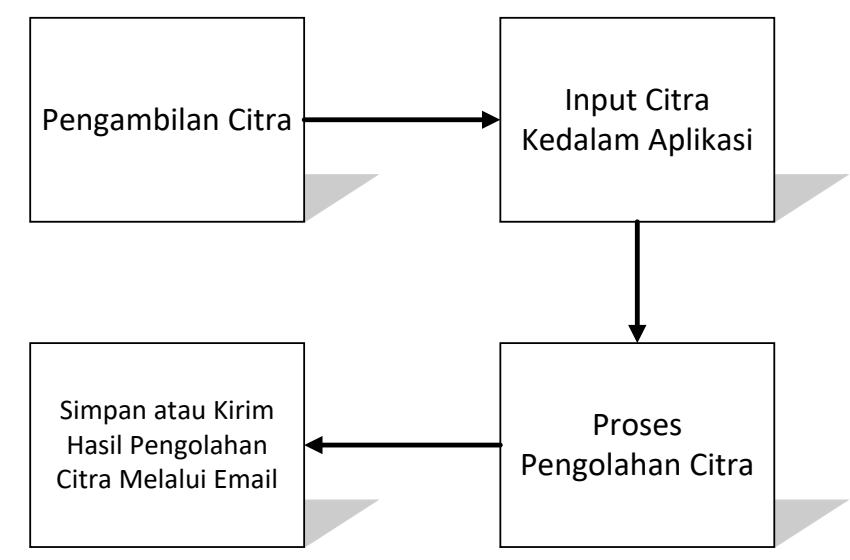


Gambar 1. Diagram blok pengolahan citra negatif menjadi citra true color. berikut:

Penjelasan dari diagram blok pengolahan citra negatif menjadi true color adalah sebagai

a. Pengambilan citra dilakukan dengan bantuan alat scan sederhana.

b. Citra yang telah diambil kemudian dimasukkan kedalam aplikasi.

c. Terdapat 2 proses dalam aplikasi pengolahan citra negatif menjadi citra true color, yaitu proses pengolahan citra menjadi citra grayscale dan citra true color.

d. Hasil pengolahan citra dapat disimpan kedalam komputer ataupun dikirim melalui email.

4. Perancangan Sistem

Sistem ini menggunakan alat sederhana yang kami buat dengan simple dan praktis kemudian hasil foto dimasukan ke aplikasi matlab yang sudah kami rancang sedemikian rupa lalu akan menghasilkan citra true color yang di inginkan.

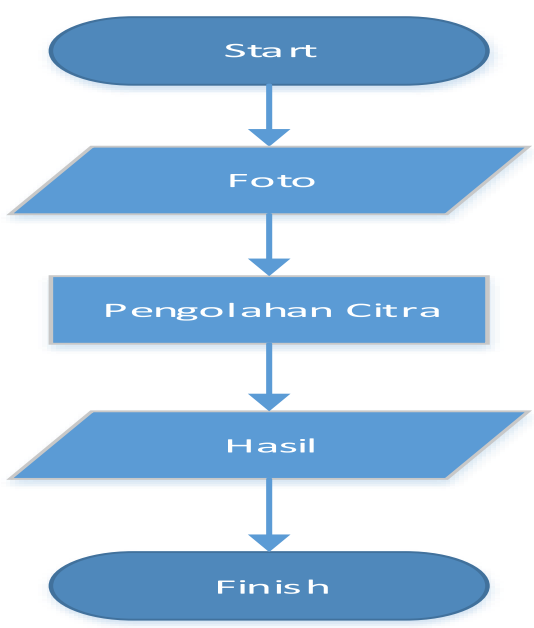

Gambar 2. diagram flowchart pengolahan citra negatif menjadi true color

5. Perancangan Alat

Alat dibuat menggunakan bahan-bahan yang mudah dicari. Berikut adalah contoh dari alat yang telah dibuat:
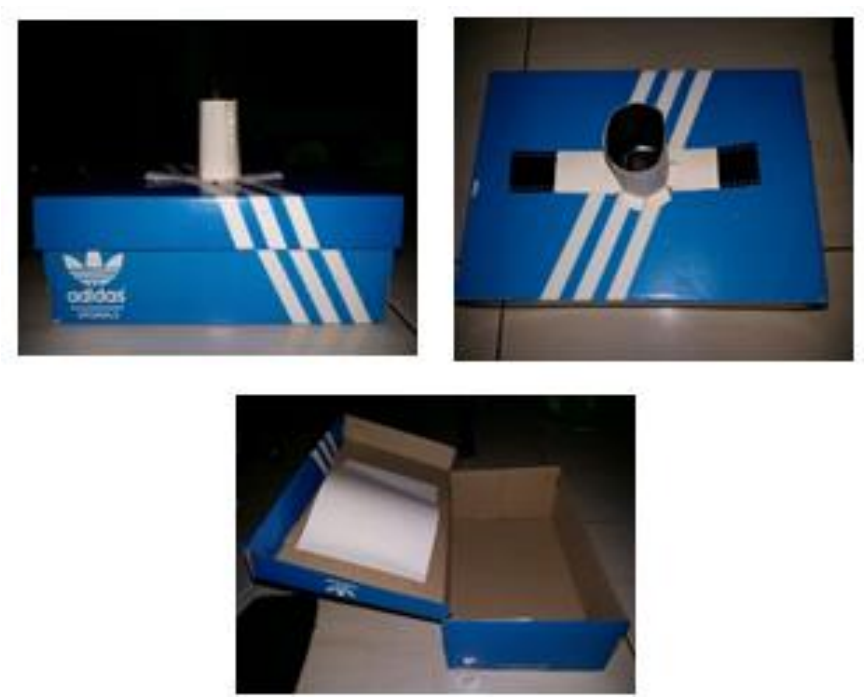

Gambar 3. Alat scan sederhana. 
Penjelasan dari pembuatan alat scan sederhana adalah sebagai berikut :

Bahan dan alat yang digunakan :
a. Kadus bekas
b. Kertas Karton
c. Kertas HVS
d. Gunting
e. Cutter
f. Penggaris
g. Lem dan Doubletip
h. Kamera Digital

6. Desain Tampilan

Tampilan antarmuka dari aplikasi ini dibuat rapi dan sederhana agar mudah digunakan. Berikut adalah rancangan tampilan antarmuka dari aplikasi pengolahan citra negatif menjadi citra true color:

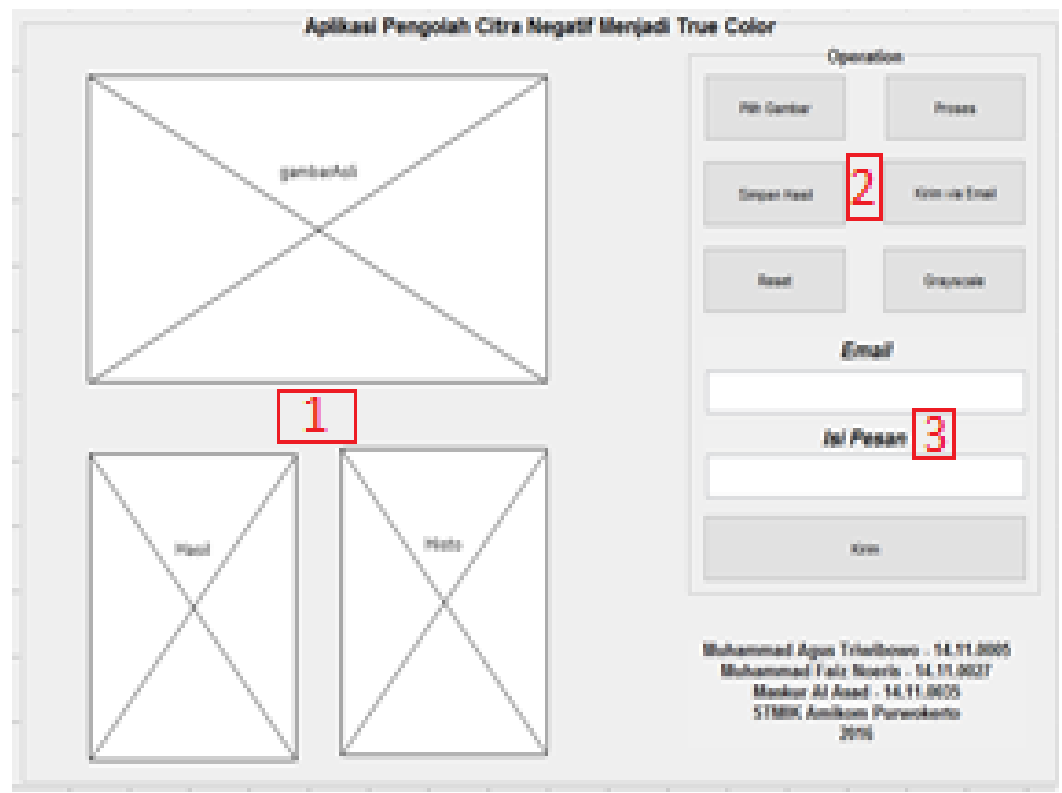

Gambar 4. Rancangan tampilan aplikasi pengolahan citra negatif menjadi citra true color.

Keterangan gambar:

a. Terdapat 3 axes, untuk menampilkan citra yang dimasukkan, citra hasil pengolahan, dan histogram.

b. Kolom untuk tombol-tombol pengoperasian.

c. Kolom yang akan muncul jika ingin mengirim hasil pengolahan citra melalui email.

Pada tahap ini dilakukan pengujian terhadap aplikasi yang telah dibuat.

Tabel 1 Tahap Pengujian

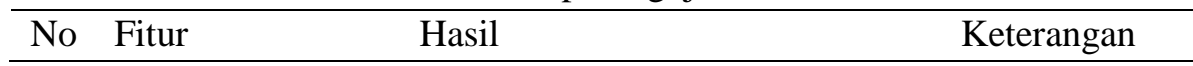


Dhanar Intan Surya Saputra, Muhammad Agus Triwibowo, Muhammmad Faiz Noeris, Maskur Alasad
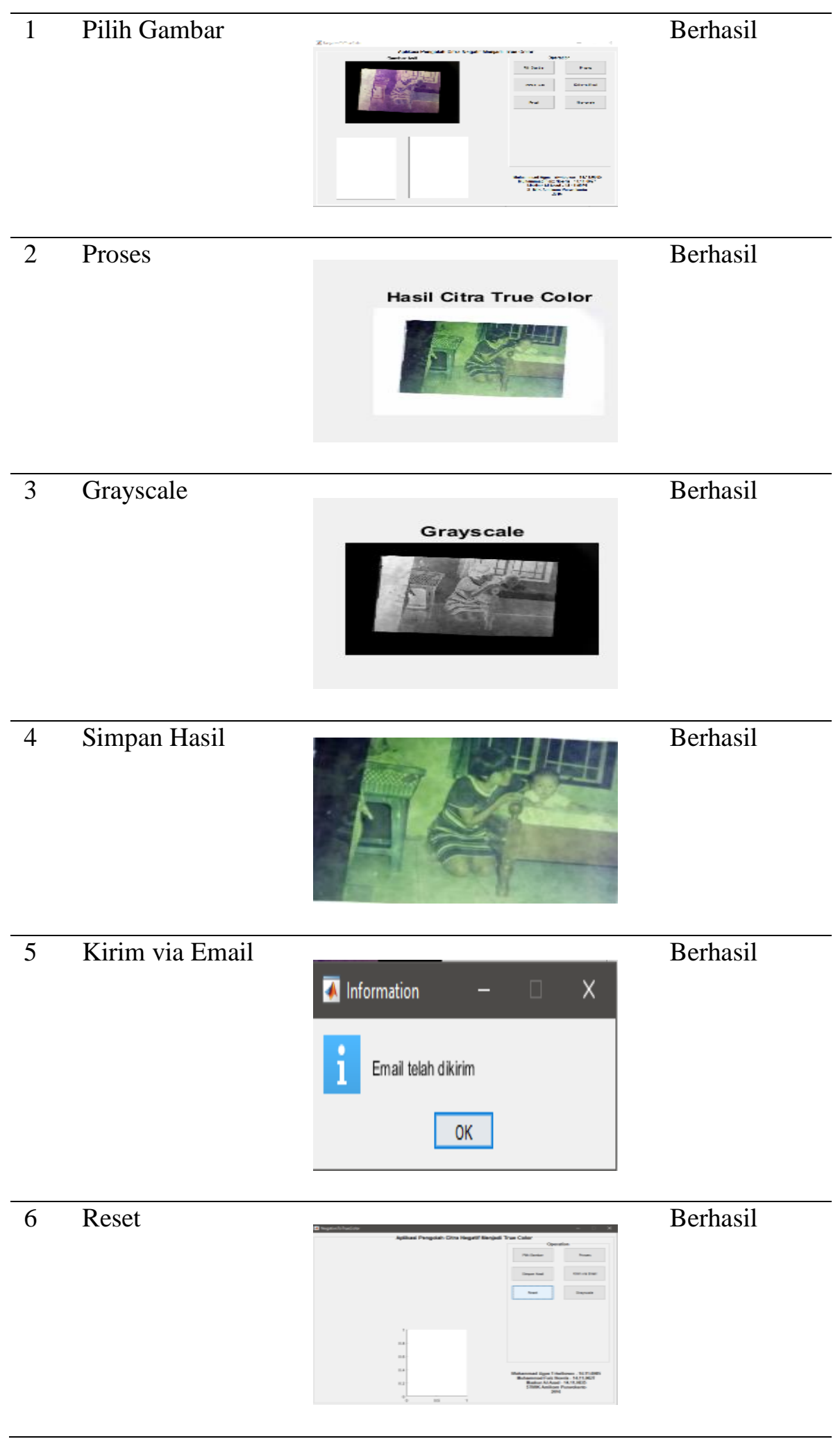

Proses pengubahan klise negatif menjadi true color menggunakan perintah:

$$
\text { tc }=255-1-\text { realimage }
$$


Variable realimage menyimpan gambar original atau citra negatif yang akan diubah menjadi citra true color dengan tingkat gray level 255 ( 8 bit). Hasil dari pengolahannya seperti pada Gambar 4 berikut:
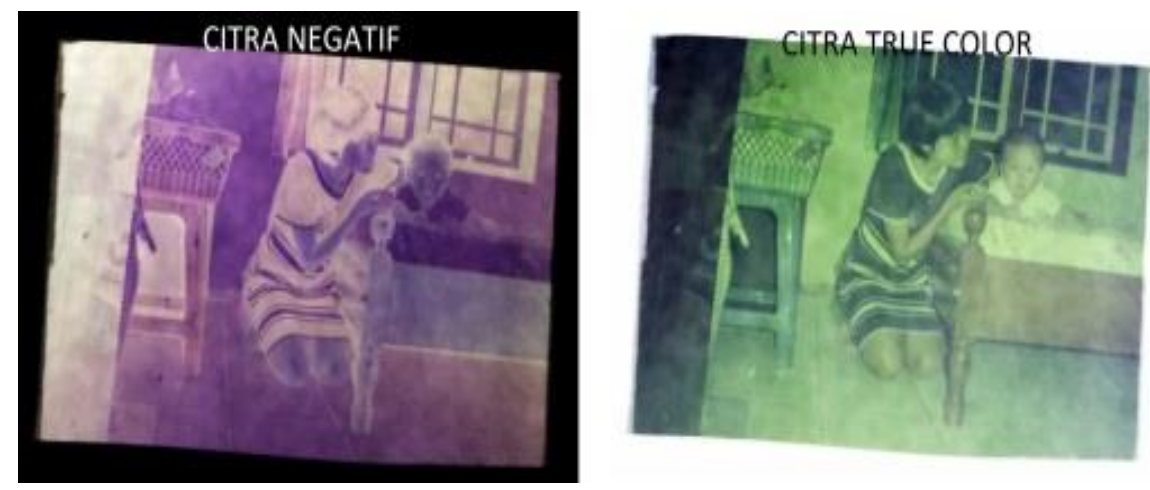

Gambar 5 Hasil pengolahan citra negatif menjadi true color.

Proses pengambilan citra negatif klise bisa dilakukan dengan kamera digital ataupun kamera smartphone, dan dibantu dengan pencahayaan dari lampu smartphone maupun dari sumber lampu lainya.

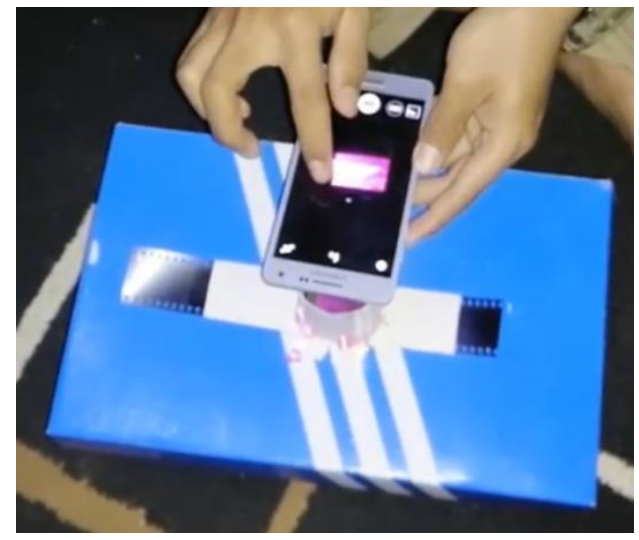

Gambar 6. Proses pengembalian citra negatif klise

Berikut adalah tampilan awal ketika aplikasi dibuka:

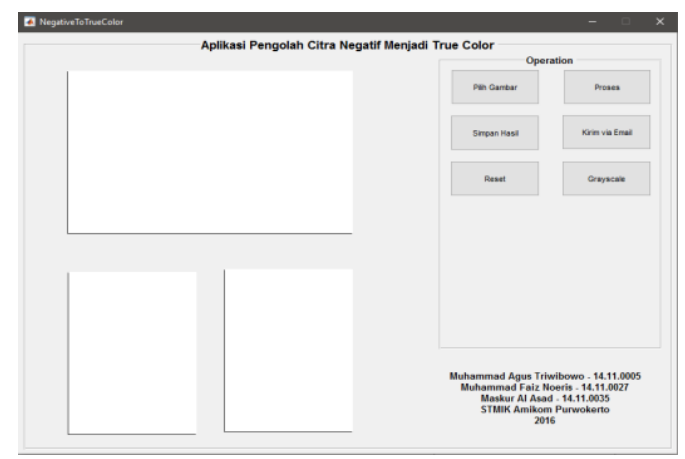

Gambar 7. Tampilan awal aplikasi. 
User akan memilih citra digital yang akan diproses kedalam aplikasi dengan format *.jpg, *.bmp.

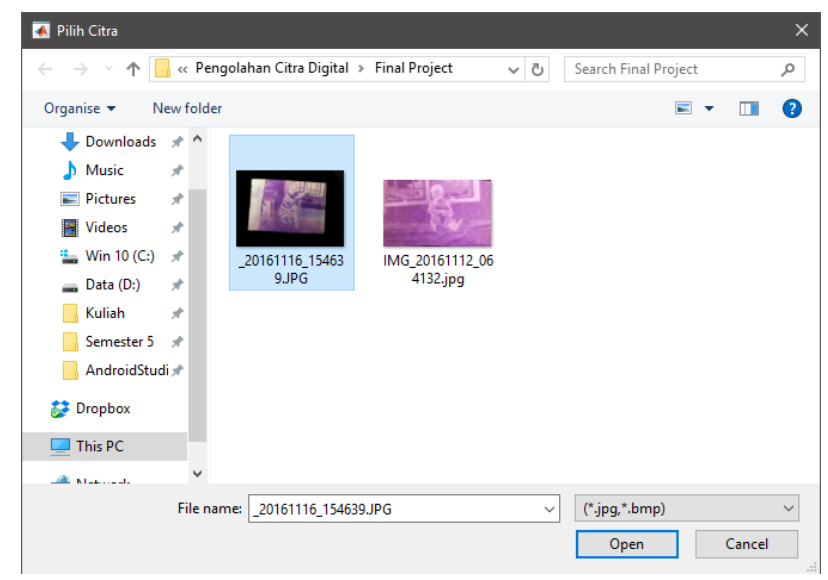

Gambar 8. Dialog untuk membuka file.

Citra yang telah dipilih akan diolah menjadi citra true color ataupun citra grayscale.

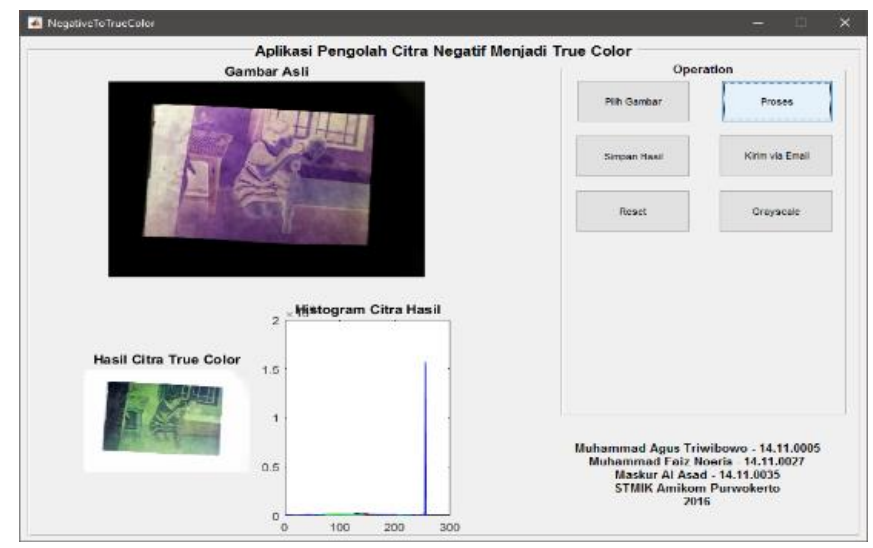

Gambar 9. Tampilan aplikasi setelah dilakukan proses pengolahan citra.

Setalah dilakukan pengolahan citra, hasi dari pengolahan tersebut dapat disimpan ke dalam komputer atau dikirim melalui email. Bisa dilihat pada Gambar.9, hasil perubahan citra negatif menjadi true color.

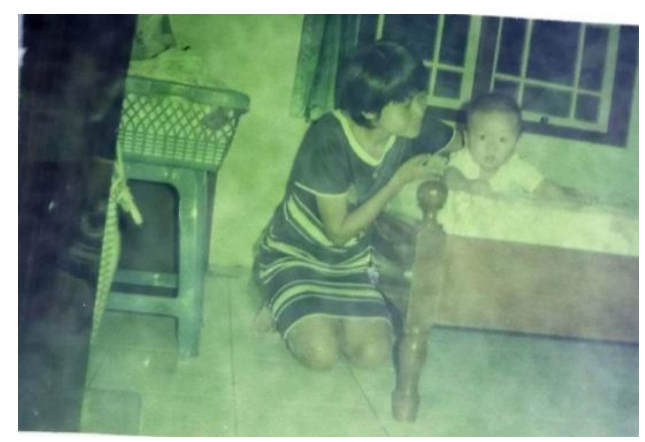

Gambar 10. Hasil citra true color. 
Jika ingin melakukan pengiriman melalui email tekan tombol "Kirim via Email" kemudian akan muncul kolom untuk mengisi email yang akan dituju dan pesan yang akan disampaikan kepada penerima.

Citra hasil pengolahan harus disimpan terlebih dahulu sebelum dikirim.

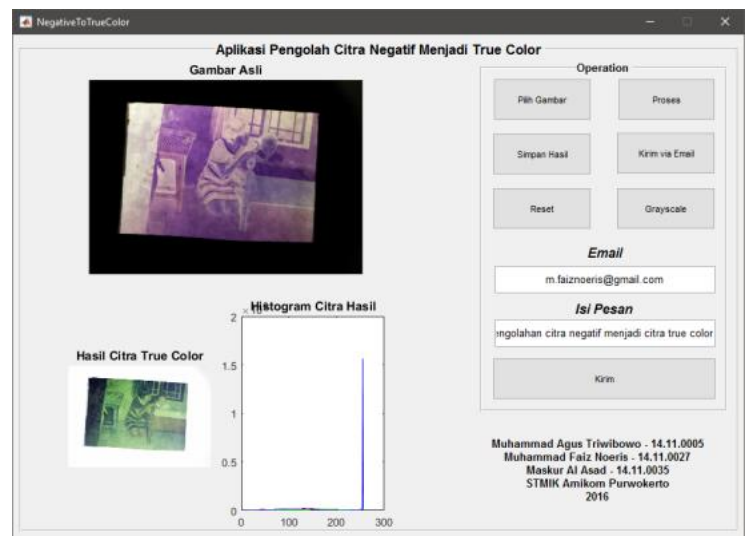

Gambar 11. Tampilan aplikasi saat proses pengiriman email.

Ketika citra telah berhasil dikirim, akan muncul notifikasi MessageBox. Seperti yang telah ditampilkan pada Gambar 12.

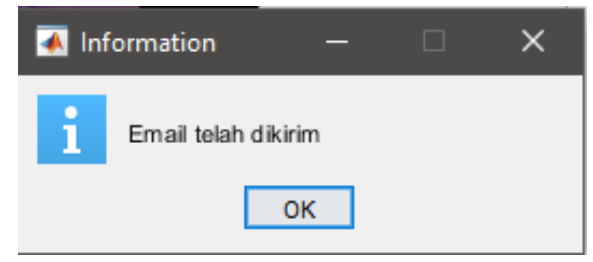

Gambar 12. MessageBox yang berisi pesan "Email telah dikirim".

Dari hasil uji coba semua fitur sudah bekerja secara sempurna tanpa adanya error dari masing-masing program yang telah dibuat.

\section{KESIMPULAN}

Dari hasil penelitian dan pembahasan yang telah disusun dapat ditarik kesimpulan sebagai berikut :

a. Aplikasi ini dapat digunakan sebagai pengolah citra digital yang berasal dari klise (negative) foto berupa citra invert menjadi citra true color.

b. Aplikasi yang dikembangkan dapat melakukan proses pengolahan citra digital yaitu dengan proses load image (pilih gambar), proses grayscale, proses true color, proses histogram, proses save image (simpan gambar) dan hingga proses kirim email

c. Desain tampilan antar muka yang simple dan tidak membingungkan bagi pengguna.

d. Kualitas gambar yang dihasilkan pada citra true color masih kurang halus, terdapat bercakbercak. Hal ini dikarenakan pada saat pengambilan foto klise masih terdapat bayangan dari kertas HVS yang berfungsi sebagai peredup cahaya ikut terekam oleh kamera.

e. Hasil output citra true color dari aplikasi yang dikembangkan masih ada kekurangan, seperti pada pengujian jika klise cenderung berwarna ungu maka citra yang dihasilkan pada true color akan cenderung hijau

\section{SARAN}


Diharapkan pada penelitian selanjutnya untuk membuat alat scan sederhana yang telah terinstal dengan sumber cahaya dan alat peredam cahaya agar proses pengambilan gambar lebih mudah dan dapat menghasilkan warna yang lebih halus.

\section{UCAPAN TERIMA KASIH}

Kami selaku penyusun jurnal mengucapkan terima kasih terutama kepada Allah SWT, kemudian kepada STMIK AMIKOM Purwokerto, kampus tercinta.

\section{DAFTAR PUSTAKA}

[1]. Putro, M.D., Adji, T.B., dan Winduratna, B., 2012, Sistem Deteksi Wajah dengan Menggunakan Metode Viola-Jones, SciETec - Seminar Nasional "Science, Engineering and Technology"-2012, Universitas Brawijaya Malang.

[2]. Saputra, D.I.S., Amin, K.M., 2016, Face Detection and Tracking Using Live Video Acquisition in Camera Closed Circuit Television and Webcam, International Conference on Information Technology, Information Systems and Electrical Engineering, ICITISEE 2016, STMIK AMIKOM Purwokerto, Yogyakarta.

[3]. Hestiningsih, I, 2008, Pengolahan Citra Digital, Gava Media, Yogyakarta.

[4]. Yahya, K., Yuliana, M., 2011, Aplikasi Kompresi Citra Digital Dengan Menggunakan Teknik Konversi Jpeg Dengan Fungsi GUI Pada Matlab, Skripsi, Jurusan Teknik Informasi Sekolah Tinggi Teknik Surabaya.

[5]. Sutoyo, T., Mulyanto, E., Suhartono, V., Nurhayati, O, D., Wijanarto, 2009, Teori Pengolahan Citra Digital, Penerbit Andi, Yogyakarta.

[6]. Putra, D., 2010, Pengolahan Citra Digital, Penerbit Andi, Yogyakarta.

[7]. Sukardi, 2015, Pengolahan Citra Digital dengan menggunakan Matlab, Universitas Hasanudin, Makasar.

[ 8]. Utama, Jana. 2011. "Akuisisi Citra Digital Menggunakan Pemrograman Matlab". Majalah Ilmiah UNIKOM. Vol.9, No. 1.

[9]. Yahya, Kurnia., Yuliana Melita. 2011. Aplikasi Kompresi Citra Digital Menggunakan Teknik Kompresi Jpeg dengan Fungsi GUI pada MATLAB. Jurnal Teknika. Volume 3 No 2 Tahun 2011.

[10]. Kurniasaria, Habriana Budi., Susilo, Isa Akhlis. 2012. Penerapan Pengolahan Citra Digital Dengan Matlab 7.1 Pada Citra Radiografi. Unnes Phisics Journal. Jurusan Fisika, FMIPA UNNES, dipublikasikan oleh http://journal.unnes.ac.id/sju/index.php/upj diakses pada tanggal 13 Januari 2017. 